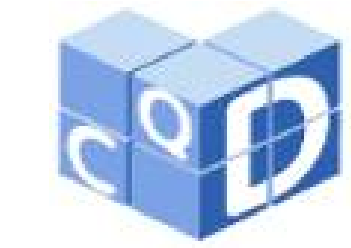

Revista Eletrônica

Paulista de Matemática

ISSN 2316-9664

Volume 17, dez. 2019

Edição Ermac

Marcos Henrique de Paula Dias da Silva

UNESP - Universidade Estadual Paulista "Júlio de Mesquita Filho"

calibum@usp.br

\section{A Wild Function Appeared: um jogo digital so- bre cálculo diferencial}

A Wild Function Appeared: a digital game about differential calculus

\section{Resumo}

A importância do cálculo diferencial hoje é quase indiscutível para maioria dos cursos ligados às ciências exatas. Contudo no contexto brasileiro, o primeiro contato dos estudantes com este conteúdo geralmente ocorre somente no ingresso à universidade, potencializando um deficit inicial no seu desenvolvimento. Dessa forma, um trabalho em torno da divulgação científica do cálculo diferencial e na elaboração de recursos auxiliares para sua aprendizagem, poderiam contribuir no desempenho e interesse dos estudantes nestes cursos. $\mathrm{O}$ presente trabalho discute os conceitos e dilemas envoltos na construção de um jogo digital com esta temática, tomando como base um jogo digital e um conteúdo de divulgação científica já existentes e ambos com uma ampla divulgação.

Palavras-chave: Cálculo diferencial. Jogo digital. Aprendizagem.

\begin{abstract}
The importance of differential calculus today is almost unquestionable for most exact science courses. However, in the brazilian context, students first contact with this content usually occurs only upon university entrance, increasing an initial deficit in its development. Thus, a work around the scientific dissemination of differential calculus and the elaboration of auxiliary resources for their learning could contribute to the students performance and interest in these courses. This paper discusses the concepts and dilemmas involved in the construction of a digital game with this theme, based on an existing digital game and a popular science content and both with wide dissemination.
\end{abstract}

Keywords: Differential calculus. Digital game. Learning. 


\section{Introdução}

O cálculo integral surge nos problemas de superfície e volume dos antigos gregos como Eudoxo e Arquimedes há mais de 2.500 anos. Ambos usavam o "método de exaustão", que era registrar e reescrever a figura em polígonos, depois aumentar o número de faces, formar triângulos e calcular suas áreas isoladamente. $\mathrm{O}$ cálculo diferencial entretanto surge apenas no século XVII a partir do problema da tangente, com principais contribuições atribuídas a Pierre Fermat, John Wallis, Isaac Barrow, Isaac Newton e Gottfried Leibniz (STEWART, 2013).

Reconhecendo a importância do cálculo diferencial, destacamos sua divulgação científica tomando como referência dois trabalhos que se valem da imersão da cultura japonesa no Brasil: Guia mangá de cálculo: diferencial e integral (KOJIMA; TOGAMI, 2010); Guia mangá de números complexos (OCHI; ISHINO, 2010). Ambas tratam a partir de quadrinhos japoneses, conceitos de matemática, hora aplicáveis ao papel de uma jovem jornalista ou nas frustrações de um calouro cursando graduação na área de ciências exatas.

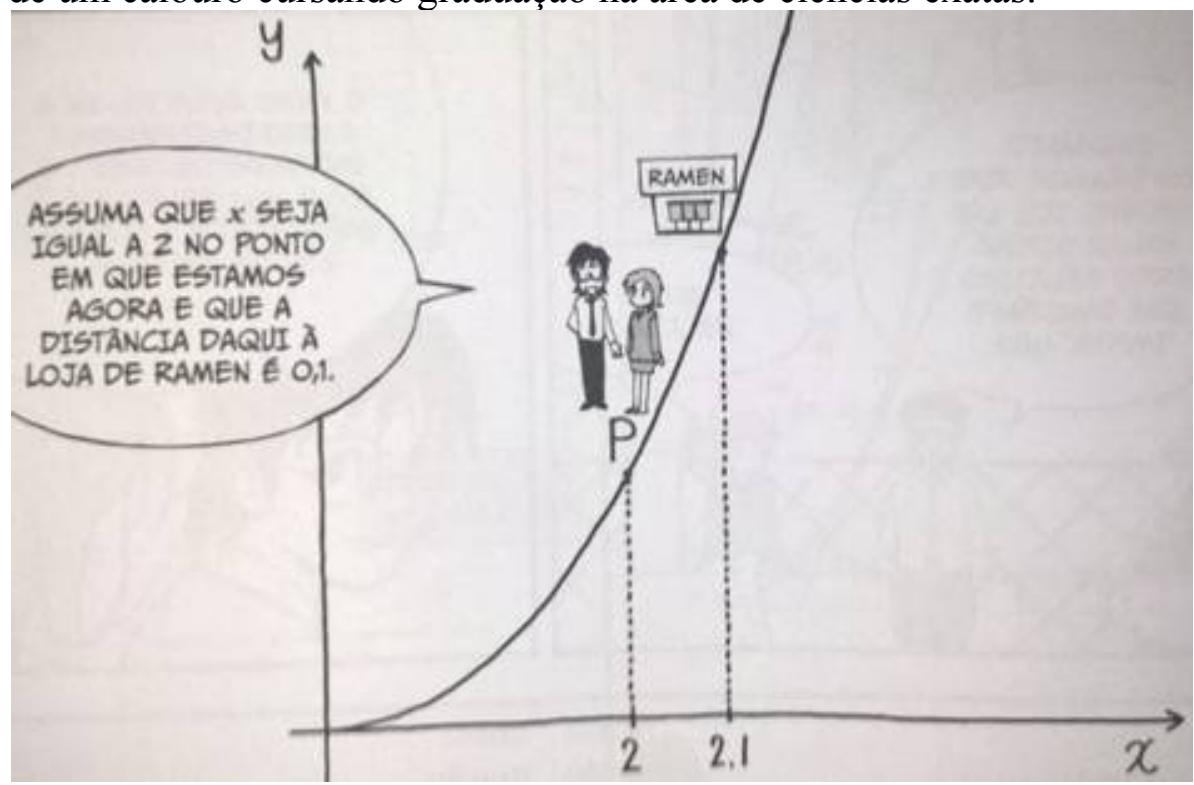

Figura 1 - Guia mangá de cálculo: diferencial e integral (KOJIMA; TOGAMI, 2010, p. 28).

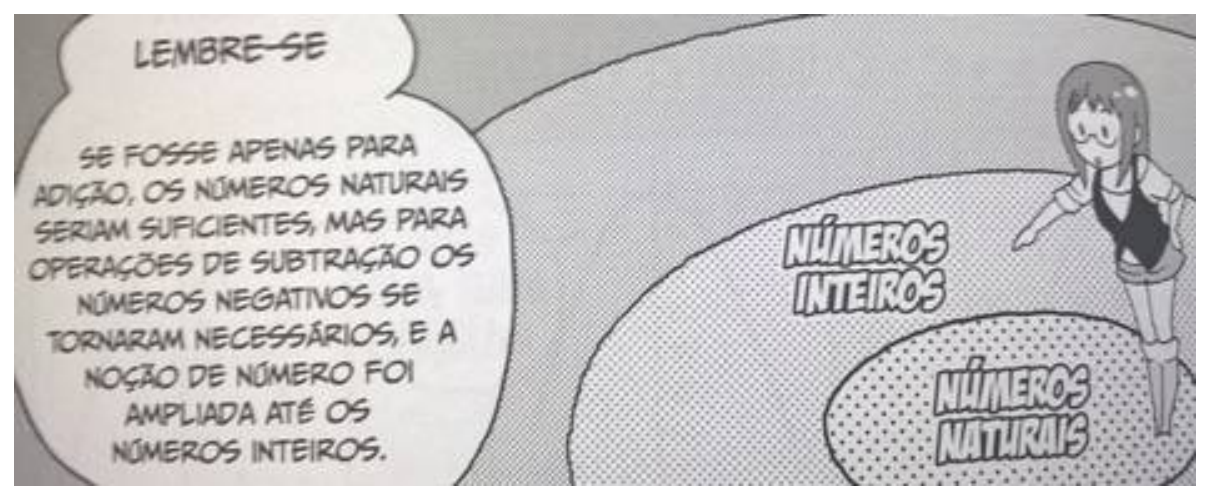

Figura 2 - A direita Guia mangá de números complexos (OCHI; ISHINO, 2010, p. 28).

No viés da divulgação científica do cálculo diferencial, cabe destacar uma famosa piada que circula pela internet e se vale também da imersão da cultura japonesa no ocidente. Ela faz referência aos jogos digitais de gameboy Pokémon versão red ou versão blue, e para elucidar os conceitos por base deste conteúdo, precisamos antes retomar alguns aspectos destes jogos. 


\subsection{Pokémon versão red ou blue}

Pokémon é uma franquia criada por Satoshi Tajiri em 1995. Ela é centrada em criaturas ficcionais chamadas pokémon, que os seres humanos capturam e os treinam para lutarem um contra o outro. Os jogos para gameboy Pokémon versão red ou Pokémon versão blue, foram lançados nos EUA em 1998. Neles, o protagonista é um garoto que no decorrer de sua viagem precisa enfrentar pokémons usando para isto outros pokémons que o mesmo capturou e treinou. As batalhas acontecem a partir das escolhas de golpes que um pokémon conhece e pode usar, o confronto geralmente dura até um dos pokémons fique fraco e desmaie.

Os pokémons possuem tipos distintos que lhes conferem vantagens e desvantagens de acordo com suas propriedades, por exemplo: água tem vantagem contra fogo; fogo tem vantagem contra planta. Assim, lançar um ataque de fogo contra um pokémon do tipo água, surte pouco efeito no pokémon do tipo água, da mesma foram que lançar um ataque de planta contra um pokémon do tipo fogo, surte pouco efeito no pokémon do tipo fogo. Nestas ocasiões aparece uma mensagem dizendo que "isto não foi muito efetivo". Analogamente: lançar um ataque de água contra um pokémon do tipo fogo, é super efetivo no pokémon do tipo fogo; lançar um ataque de fogo contra um pokémon do tipo planta, é super efetivo no pokémon do tipo planta. Nestas ocasiões aparece uma mensagem dizendo que "isto foi super efetivo!".

$\mathrm{Na}$ Figura 3 (a esquerda) o protagonista encontra um pokémon selvagem do tipo fogo. $\mathrm{Na}$ Figura 3 (centro) nosso pokémon utiliza um ataque de planta contra o pokémon do tipo fogo. Na Figura 3 (a direita) aparece a mensagem dizendo que "isto não foi muito efetivo".

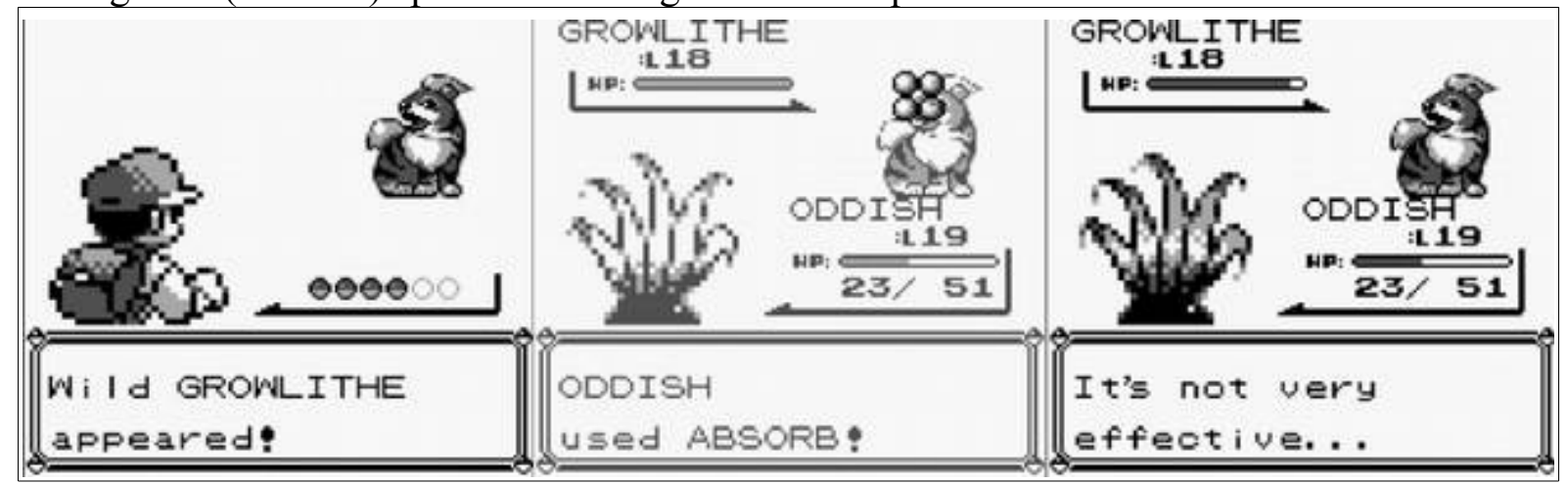

Figura 3 - Cena de batalha em Pokémon versão red (fonte própria).

Compreendendo a estrutura básica dos combates em Pokémon versão red ou versão blue, podemos apresentar o conteúdo de cálculo diferencial que circula pela internet na forma de uma piada relacionada a este jogo digital.

\subsection{Piada sobre cálculo diferencial e duas de suas variações}

A referida piada começa na Figura 4 (a esquerda) com o protagonista se encontrando com uma função selvagem (como se a função fosse um pokémon). Na Figura 4 (centro) o protagonista utiliza o ataque "derivar em função de x". Na Figura 4 (a direita) aparece a mensagem dizendo que "isto não foi muito efetivo". O humor deste conteúdo de divulgação da matemática, permeia a invariabilidade da função $\mathrm{e}^{\mathrm{x}}$ diante da ação de derivá-la em função de x. Sendo associada ao uso de um "ataque ineficiente" contra um pokémon. 


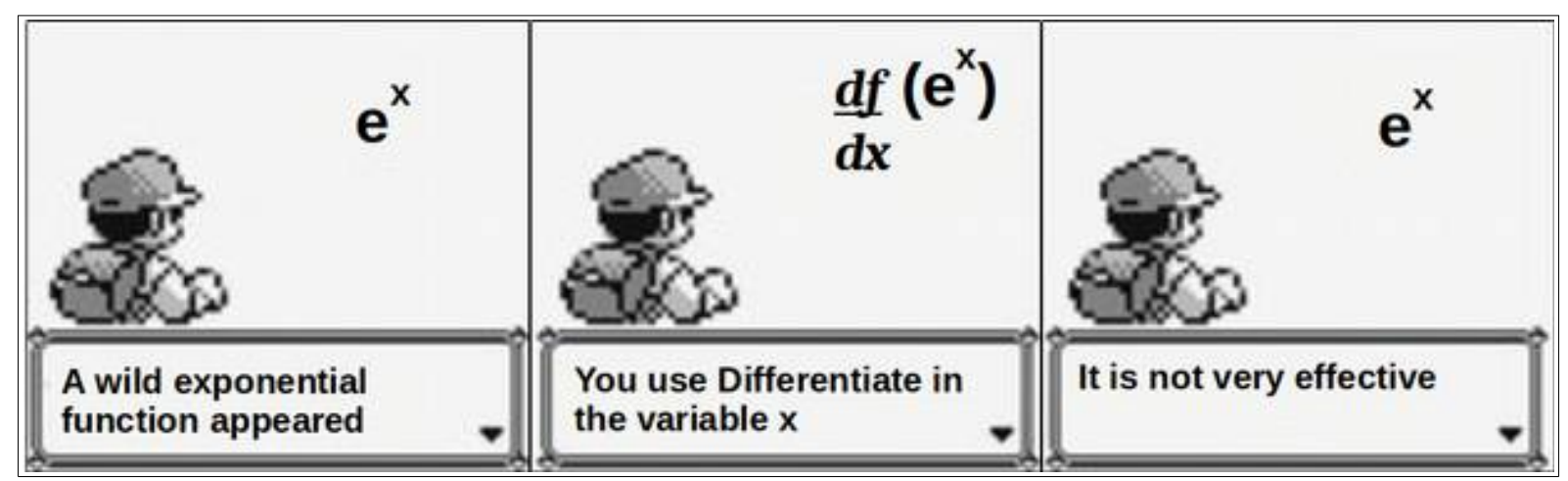

Figura 4 - Versão mais difundida da piada sobre cálculo diferencial (fonte própria).

Uma variação deste mesmo conteúdo, relaciona-se com a função $\mathrm{e}^{2 \mathrm{x}}$ na situação em que ela é derivada em função de $\mathrm{x}$, resultando $2 \mathrm{e}^{2 \mathrm{x}}$. Ela começa na Figura 5 (a esquerda) com o protagonista se encontrando com uma função selvagem. Na Figura 5 (centro) o protagonista utiliza o ataque "derivar em função de x". Na Figura 5 (a direita) em vez da mensagem "isto não foi muito efetivo", surge a mensagem “onde está o seu Deus agora?", como uma provocação ao protagonista, dado que agora a função está duas vezes mais "poderosa".

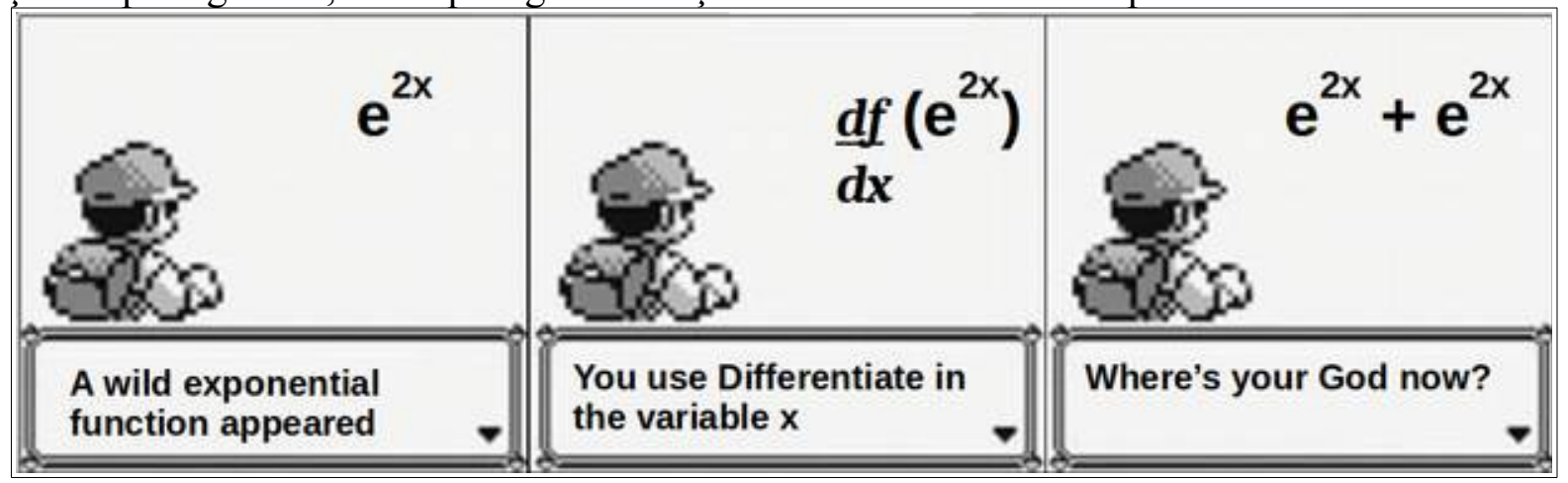

Figura 5 - Variação da piada sobre cálculo diferencial (fonte própria).

Uma terceira variação deste conteúdo, relaciona-se com a função $\mathrm{e}^{\mathrm{x}}$ na situação em que ela é derivada em função de y, resultando 0. Ela começa na Figura 6 (a esquerda) com o protagonista se encontrando com uma função selvagem. Na Figura 6 (centro) o protagonista utiliza o ataque "derivar em função de y". Na Figura 6 (a direita) aparece a mensagem dizendo que "isto foi super efetivo!”. O humor deste conteúdo de divulgação da matemática, permeia o fato da função $\mathrm{e}^{\mathrm{x}}$ ser equivalente a uma constante quando derivamos em função de $\mathrm{y}$. Sendo associada ao uso de um "ataque super efetivo" contra um pokémon.

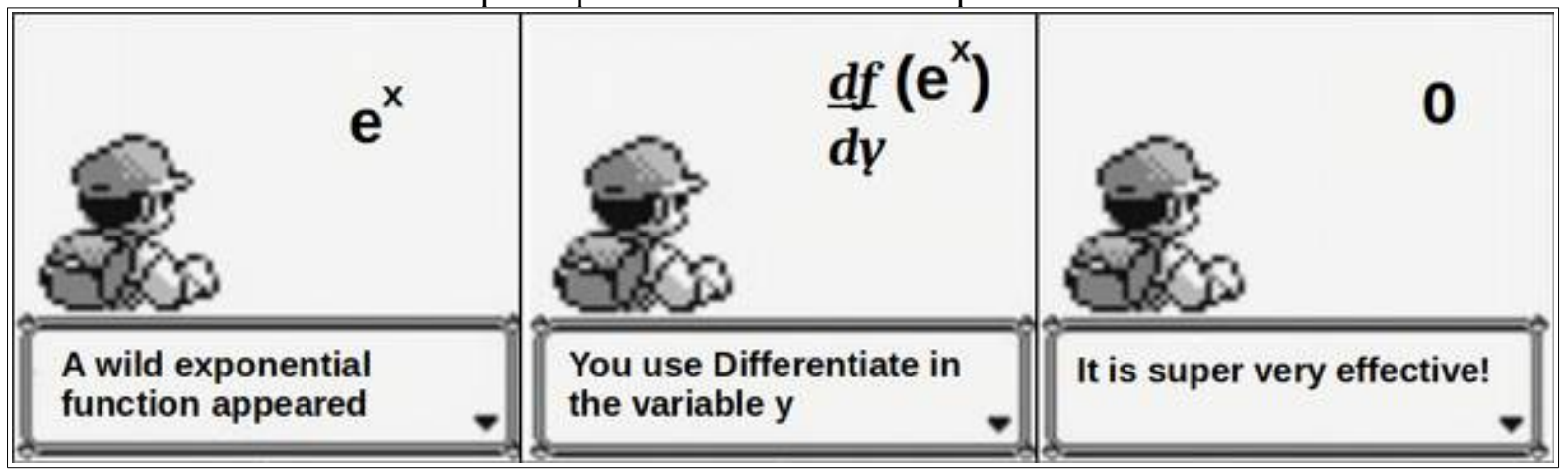

Figura 6 - Variação da piada sobre cálculo diferencial (fonte própria). 


\subsection{Objetivos}

Podemos entender o Game design document segundo Rogers (2012), como um modelo de negócios para a elaboração de um jogo, nele são determinadas as metas, especificidades, aspectos técnicos e conceituais que deverão ser observados e trabalhados pela equipe de produção. O intuito deste modelo de documento é que ao ser combinado com profissionais capacitados, seja possível identificar pontos a serem corrigidos antes de sua construção, orientar ajustes a fim de melhorar o produto em desenvolvimento e desviar-se o mínimo daquilo que se espera alcançar a medida do avanço nas etapas do projeto original.

Dessa forma, o presente artigo tem como objetivo a construção de conceitos que viabilizem a interatividade do usuário com um conteúdo associado a este que já possuí uma ampla circulação. Nessa proposta idealizamos a estrutura de um jogo digital, relacionando-se principalmente ao contexto inicial que se baseia nos jogos digitais Pokémon versão red ou blue. Assim, apresentamos na forma de um Short game design document, como definido por por Motta e Trigueiro Júnior (2013), sendo um recurso textual-teórico com semelhanças a um Game design document, construído para se adequar ao plano de desenvolvimento de um jogo de pequeno porte.

\section{Conceitos}

Na interpretação de Chandler (2012), o conceito inicial de um jogo digital é uma pergunta passada à equipe de desenvolvimento como um problema a ser resolvido. Um termo que pela definição se assemelha a questão/problema de pesquisa na produção acadêmica (GIL, 2002). Assim quando pensamos no prisma dos jogos digitais como recursos auxiliares à educação, é preciso uma formulação de perguntas que abarquem ao mesmo tempo a construção de uma dinâmica entre jogador e artefato (jogo), como também, consiga cobrir o conteúdo ao qual estará auxiliando no processo de aprendizagem.

\subsection{Exemplos}

A título de exemplo, apresentaremos alguns jogos digitais e seus respectivos conceitos iniciais. A escolha destes jogos digitais levou em conta a familiaridade do pesquisador com os mesmos, seu registro na forma de trabalhos acadêmicos e o fato destes terem como propósito o auxílio na aprendizagem de matemática, não correspondendo diretamente aos aspectos curriculares desta disciplina tratadas na Educação Básica. Pois como propomos uma abordagem envolvendo cálculo diferencial, o mesmo ainda que contribua para a aprendizagem de matemática, também não corresponde diretamente aos conteúdos curriculares desta disciplina para aqueles externos aos cursos universitários ligados às ciências exatas.

Handles in Scratch 2.0, é um jogo digital projetado em referência à handles que significa manejar ou maçanetas, associado ao jogo no sentido de arrastar e manejar operações matemáticas. Enquanto scratch significa rabiscar, rascunhar, associando à ideia do jogador poder experimentar o jogo sem medo de errar, até aprender. Traz como conceito inicial, a pergunta: como o jogador poderia usar métodos numéricos para jogar? (SILVA, 2017, SILVA, 2018b)

Game-recover, é um jogo digital projetado para que os jogadores desenvolvam uma experiência prática de programar a partir da implementação de correções no código-fonte incompleto do próprio jogo digital. Traz como conceito inicial, a pergunta: como deve ser um jogo digital envolvendo o conserto de si mesmo a medida que é jogado?(SILVA, 2018a)

ExQuest, é um jogo digital projetado em referência ao software Excel e a palavra quest (do idioma inglês significa buscar, mas seu uso é muito presente em jogos digitais referente à missões e aventuras voltadas para que os personagens recebam recompensas), faz uso de ilustrações geradas dos caracteres textuais da planilha eletrônica e envolve problemas com trata- 
mentos de pequenos bancos de dados disponíveis e operacionalizáveis com as próprias funções das planilhas eletrônicas. Traz como conceito inicial, a pergunta: como o jogador usaria funções matemáticas de uma planilha eletrônica em um jogo do gênero adventure? (SILVA, 2019)

\subsection{Reflexões}

Dessa forma, o conceito inicial de um jogo tem como finalidade orientar a sua construção dentro de uma problemática definida. Assim, antes de enunciar o conceito do jogo digital proposto, é pertinente apresentarmos as principais reflexões a cerca desta problemática e que proporcionaram o desenvolvendo deste conceito.

Reflexão 1) Porque criar monstros com comportamentos, vantagens e desvantagens controladas por funções matemáticas para fazer um jogo digital, quando podemos usar as próprias funções da matemática como monstros reais? Vista que estas já representam na realidade "monstros" do dia a dia de muitos estudantes universitários.

Reflexão 2) Porque arbitrariamente escolher fórmulas de ataque e dano contra os "monstros" definidos por propriedades matemáticas? Dado que existem inúmeras técnicas/regras na matemática para resolver/simplificar/reduzir problemas.

\subsection{Conceito inicial}

Baseado nestas reflexões, propomos o conceito inicial de um jogo digital intitulado "A Wild Function Appeared" em referência direta ao contexto de Pokémon versão red ou blue, do qual desejamos aproveitar a ampla difusão. Dessa forma, este jogo tem como essência trazer consistência e dinâmicas interativas a uma generalização do conteúdo de divulgação científica matemática que circula na internet conforme apresentado na Introdução. Seu conceito inicial pode ser descrito na pergunta: como seriam as interações de um estudante de cálculo usando ferramentas do cálculo diferencial em batalhas contra funções matemáticas?

\section{Tratamento}

Tendo em mente o conceito inicial deste jogo, prosseguimos para um trabalho exploratório na lógica intrínseca às dinâmicas do jogo digital original ao qual este se embasaria. Formulamos como primordial, a definição de "funções de ataque" que serão utilizados contra as funções matemáticas adversárias, análogas aos ataques que um pokémon utiliza contra o outro.

\subsection{Funções de ataque}

Baseado no contexto original de divulgação, temos como funções necessárias para associar este novo conteúdo ao já existente, as seguintes "funções de ataque":

1. derivada da função em relação a x;

2. derivada da função em relação a y.

Em cima desta questão, faz-se sentido observar que no universo original do jogo digital, os pokémons possuem 4 opções de ação contra o outro pokémon. Dessa forma, considerando que abrangeremos funções diferenciáveis (pelas primeiras duas "funções de ataque" já definidas), cabe trabalhar com outras duas "funções de ataque" ligadas ao cálculo diferencial, neste caso, optamos pelas:

1. antiderivada da função em relação a x; 
2. antiderivada da função em relação a y.

Por simplicidade, dado que para uma função existam infinitas antiderivadas, consideraremos apenas a antiderivada ${ }^{1}$ da função cujo valor da constante seja igual a 0 .

\subsection{Incerteza do jogo}

Definidas as "funções de ataque", chegamos no fator de complexidade das funções que serão atacadas. Pois como um jogo digital, precisamos considerar o tipo de incerteza (ou contingência) perceptível pelo jogador. Na visão de Costikyan (2013) baseado na lista de incertezas tratadas em seu trabalho sobre incertezas nos jogos digitais, podemos associar a percepção das reações da função mediante os efeitos de derivar e antiderivar em função de x e y, enquadraria como uma incerteza do tipo solução, no qual o jogador precisa solucionar o problema de forma total ou parcial, e sua incerteza de decisão envolve a dúvida sobre os resultados imaginados.

Ainda com base na visão de Costikyan (2013) sobre as incertezas presentes nos jogos digitais, podemos associar a problemática deste jogo, com a incerteza de complexidade analítica, pois as funções de derivada e antiderivada em x e y não são comutativas. Logo, temos para cada escolha do jogador, quatro novos ramos na sua árvore total de escolhas. Dessa forma, para $\mathrm{N}$ ações contra uma função, temos $4^{\mathrm{N}}$ possibilidades de resultado, o que a enquadra como uma incerteza de complexidade analítica, dado que o grande número de ramificações torna obscura a percepção dos desencadeamentos resultantes de uma escolha.

Conhecidas as "funções de ataque", podemos determinar no viés das incertezas de solução e de complexidade analítica, que o jogador deva ser capaz de perceber rapidamente pelo menos uma solução parcial ou ter uma ideia das consequências envolvidas diretamente a uma escolha. Assim, para uma proposta inicial de jogo digital, podemos considerar as funções cuja ideia de derivada e antiderivada sejam facilmente obtidas, tais como as funções polinomiais, algumas trigonométricas simples e exponenciais.

\subsection{Configuração de jogo}

Considerando a construção do mesmo como um jogo digital, faz-se necessário manter a atenção a aspectos como condição de vitória, condição de derrota e processo iterativo de interação. Dessa forma, estruturamos como $0^{\mathrm{a}}$ jogada, aquela na qual o jogador se encontra antes da batalha começar, nela aparecem as suas quatro funções de ataque disponíveis e o score do personagem no curso, o qual inicia com seu valor máximo, ou seja, 10.

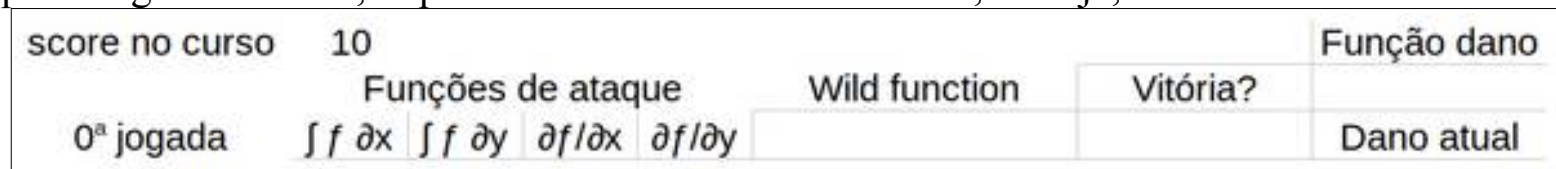

Figura 7 - Protótipo da interação do jogo construído em uma planilha eletrônica (fonte própria).

A função que ele enfrentará aparecerá nesta $0^{\mathrm{a}}$ jogada, e com ela são definidas as condições de vitória a serem satisfeitas e a função causadora de dano no score do seu curso. Também é liberado o espaço para ação na $1^{a}$ jogada.

1 Uma função $F$ é denominada uma primitiva ou antiderivada de $f$ num intervalo I se $F^{\prime}(x)=f(x)$ para todo x em I. Teorema: Se F é uma primitiva de f em um intervalo I, então a primitiva mais geral de $\mathrm{f}$ em I é $\mathrm{F}(\mathrm{x})$ $+\mathrm{C}$, onde C é uma constante arbitrária (STEWART, 2013, p. $310-311$ ).

SILVA, M. H. de P. D. da. A wild function appeared: um jogo digital sobre cálculo diferencial. C.Q.D.- Revista Eletrônica Paulista de Matemática, Bauru, v. 17, p. 1-12, fev. 2020. Edição Ermac.

DOI: 10.21167/cqdvol17ermac202023169664mhpds0112 Disponível em: http://www.fc.unesp.br/\#!/departamentos/matematica/revista-cqd/ 


\begin{tabular}{|c|c|c|c|c|}
\hline score no curso & 10 & \multicolumn{2}{c}{} & Função dano \\
& Funções de ataque & Wild function & Vitória? & $|f(1,1)|$ \\
\hline $\begin{array}{c}0^{\mathrm{a}} \text { jogada } \\
1^{\mathrm{a}} \text { jogada }\end{array}$ & $\int f \partial \mathrm{x} \int f \partial \mathrm{y} \partial f / \partial \mathrm{x} \partial f / \partial \mathrm{y}$ & $\mathrm{x}^{2}+\mathrm{xy}+\mathrm{y}^{2}$ & $|f(4,0)|<2$ & Dano atual \\
\hline
\end{tabular}

Figura 8 - Protótipo da interação do jogo construído em uma planilha eletrônica (fonte própria).

O jogador então realiza uma ação escolhendo entre as quatro funções de ataque disponíveis para usar contra a função adversária. O resultado da sua escolha fica marcado, e implica na transformação da função apresentada na $0^{\mathrm{a}}$ jogada. Dada esta nova função, verifica a condição de vitória, caso não tenha sido atingida, calcula-se então a função de dano afetando imediatamente o score do personagem no curso e é liberado o espaço para ação na $2^{\mathrm{a}}$ jogada.

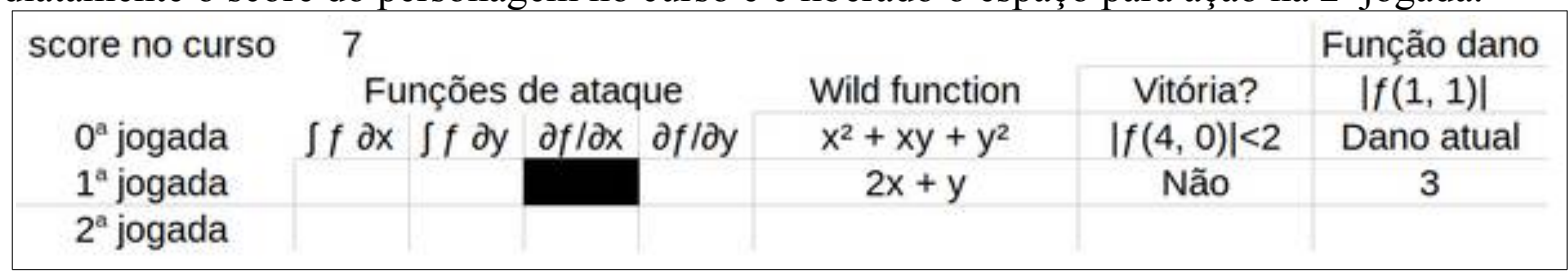

Figura 9 - Protótipo da interação do jogo construído em uma planilha eletrônica (fonte própria).

Caso a condição de vitória tenha sido atingida, a função de dano não é calculada, não liberando o espaço para ação da $3^{\mathrm{a}}$ rodada, encerrando assim o combate.

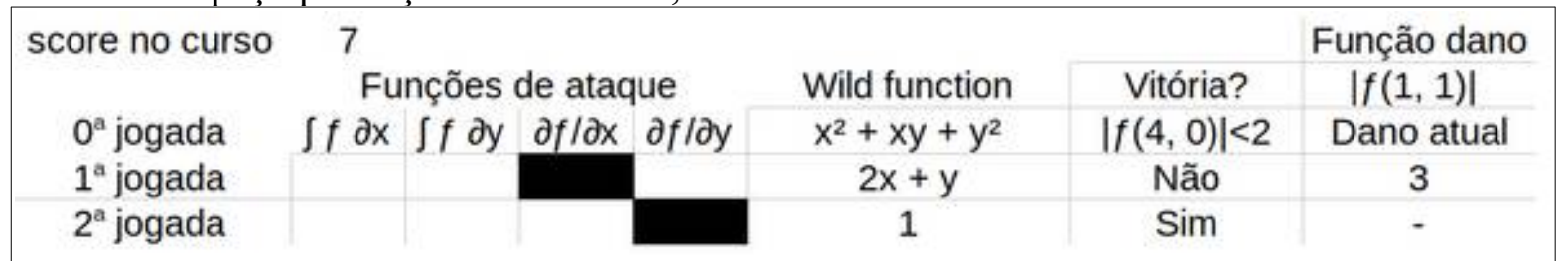

Figura 10 - Protótipo da interação do jogo construído em uma planilha eletrônica (fonte própria).

\subsection{Layout do jogo}

Considerando vários aspectos referentes à game design e desenvolvimento de jogos digitais, muito discute-se sobre o potencial de prototipagem como algo essencial para a compreensão do modelo e estudo do objeto em elaboração. Dessa forma, tomando proveito da estrutura no qual "ExQuest" (SILVA, 2018b, p. 105; SILVA, 2019) foi desenvolvido, visamos explorar de maneira simplificada as ideias anteriormente apresentadas a partir de recursos disponíveis dentro de uma planilha eletrônica. No caso deste protótipo, a automação ainda não se vê presente, servindo somente de estrutura para a inserção dos valores pelo próprio jogador. Mas sendo pretendido para as próximas versões, que a interação do jogo com o jogador, ocorra de forma automática.

\subsection{Ferramentas de jogo}

Uma habilidade necessária para interagir neste jogo é pelo menos a noção intuitiva dos resultados das funções mediante a aplicação das derivadas ou das antiderivadas em relação a $\mathrm{x}$ ou y. Por serem restritas a funções simples e não sendo a intenção deste trabalho apresentar em detalhes as regras de derivação necessárias para a tomada de decisões, enunciaremos onde estas podem ser encontradas. Ressaltando que existem várias referências correlatas, softwares e aplicações online que realizam as respectivas operações.

1. Regra da constante (STEWART, 2013, p. 158);

2. Regra da potencia (STEWART, 2013, p. 158 - 160);

3. Regra da multiplicação por constante (STEWART, 2013, p. 161); 
4. Regra da soma (STEWART, 2013, p. 161);

5. Regra da subtração (STEWART, 2013, p. 161);

6. Regra da exponencial (STEWART, 2013, p. 162 - 164);

\section{Pensamento computacional}

O pensamento computacional é um termo cunhado por Wing (2006) que expressa a maneira com que os cientistas da computação tratam os problemas para que possam quando necessário, serem resolvidos com o auxílio de computadores. Contudo a importância do pensamento computacional, se estende além dos cientistas da computação, podendo ser utilizado por todas as pessoas para tratar os mais variados problemas do cotidiano ou da vida profissional.

No Brasil, o pensamento computacional já é destaque até mesmo na BNCC ( $<$ basenacionalcomum.mec.gov.br/wp-content/uploads/2018/02/bncc-20dez-site.pdf $>$ acesso em 25-082019) no que diz respeito a disciplina de matemática no Ensino Fundamental. Destacado nos processos de ensino de matemática, como as formas de atividade que exercem ao mesmo tempo o papel de objeto e estratégia para a aprendizagem (resolução de problemas, investigação, projetos, modelagem) "são potencialmente ricas para o desenvolvimento de competências fundamentais para o Letramento Matemático (raciocínio, representação, comunicação e argumentação) e para o desenvolvimento do Pensamento Computacional (p. 264)".

Barr e Stephenson (2011) em um estudo com cientistas da computação e professores da Educação Básica dos Estados Unidos (nos EUA a ciência da computação é uma disciplina do currículo comum da Educação Básica desde 2005), exploraram compreender quais são as habilidades mais associadas a esta forma de tratar problemas. Como resultado, chegaram em 9 habilidades bastante destacadas pelos grupos investigativos. Destas 9 habilidades, discutiremos como 8 delas podem ser associada às ações de jogar "A Wild Function Appeared" (considerando a versão com interatividade automática). Ainda não conseguimos associar a habilidade paralelismo às ações de jogo, por estar relacionada ao trabalho conciliado de ações independentes. Podendo ser associada por exemplo, ao tratamento em simultâneo de várias partes de um problema maior que foi fragmentado, e ao final, permita a solução do problema original. Outra forma de perceber o paralelismo, é no tratamento de problemas distintos que podem ser executados em simultâneo sem que o processamento de um afete o outro.

\subsection{Coleta de dados}

Habilidade relacionada à estratégias para formação de bancos de dados ou localização de conteúdos a serem trabalhados (BARR; STEPHENSON, 2011). No caso do jogo apresentado, esta habilidade se relaciona à busca por referências sobre como calcular as derivadas e antiderivadas das funções, ou até mesmo na leitura seletiva das informações disponíveis na tela para o desenvolvimento de uma estratégia.

\subsection{Análise de dados}

Habilidade relacionada à tomada de decisões baseadas em interpretação de dados observados/tratados (BARR; STEPHENSON, 2011). No caso do jogo apresentado, esta habilidade se relaciona ao cálculo exato ou a noção intuitiva do resultado a ser obtido mediante determinada escolha. O que também pode envolver a interpretação das referências sobre as regras de derivação necessárias para a tomada de uma decisão com mais certeza do seu resultado. 


\subsection{Representação de dados}

Habilidade relacionada à organização dos dados e sua representatividade em outras fontes, como separar dados em categorias, ou distribuí-los em gráficos (BARR; STEPHENSON, 2011). No caso do jogo apresentado, esta habilidade se relaciona á interpretação do estado atual da função mediante a função de dano definida, ou de vitória a ser atingida. Ambas as funções tem como base a função que o jogador enfrenta, mas estão em categorias de representatividade diferente, no caso da vitória, este é o objetivo principal a ser atingido, e no caso do score do personagem no curso, esta é a condição de derrota a ser evitada.

\subsection{Abstração}

Habilidade relacionada à redução da complexidade de um problema, de modo que ele possa ser tratado com base em aspectos mais gerais (BARR; STEPHENSON, 2011). No caso do jogo apresentado, a própria manipulação das funções com base em atingir as condições de vitória e evitar as condições de derrota, reduzem a real complexidade do desafio envolvendo o cálculo diferencial. Uma vez que o jogador realmente não precisa "saber" todo o resultado, apenas atingir a condição de vitória que encerra o combate.

\subsection{Decomposição de problemas}

Habilidade relacionada à tratar um problema separando-o em partes menores de modo que a solução de todas as suas partes reduzidas possa ser unificada, solucionando o problema inicial (BARR; STEPHENSON, 2011). No caso do jogo apresentado, temos várias funções cujas operações podem ser realizadas por seus termos separadamente, como a derivada da soma ser igual a soma das derivadas. Também é possível decompor o problema de atingir as condições de vitória e evitar as condições de derrota, tratando-as separadamente, reduzindo o dano ao score do personagem no curso e se aproximando gradativamente do critério para vitória.

\subsection{Algoritmos e procedimentos}

Habilidade relacionada à construção de algoritmos e realização de procedimentos para solução de problemas, ou realização de tarefas, permitindo que se perceba ações redundantes e maximizando a eficiência (BARR; STEPHENSON, 2011). No caso do jogo apresentado, temos todo o combate como um problema a ser resolvido de forma procedimental a partir do uso de um algoritmo. Apesar de ser difícil analisar toda a árvore de possibilidade que uma ação pode proporcionar, uma estratégia de combate é a identificação de um algoritmo para obter a condição de vitória antes que seja atingida a condição de derrota. Identificado este algoritmo, então executá-lo ou tentar maximizar sua eficiência.

\subsection{Simulação}

Habilidade relacionada às estratégias de simular resultados em casos de testes, permitindo uma maior compreensão do objeto e evitando consequências maiores numa situação real (BARR; STEPHENSON, 2011). No caso do jogo apresentado, esta habilidade se relaciona ao fato do próprio objeto ser um jogo digital, logo suas consequências são reduzidas, permitindo que o jogador as explore e experimente sem o risco que poderiam existir em um contexto de avaliação, no qual uma falha conceitual afetaria seu real score no curso.

\subsection{Automação}

Habilidade relacionada à automatizar processos, de modo que estes se realizem mediados por um sistema independente (BARR; STEPHENSON, 2011). No caso do jogo apresentado, esta habilidade se relaciona ao fato do próprio jogo responder mediante as ações do jogador com as "funções de ataque". Assim, o jogador combatendo as funções, pode imediatamente 
obter seu resultado realizando um ataque específico contra ela, dado que o sistema neste caso, seria automatizado para retornar as derivadas e antiderivadas de cada função em combate.

\section{Considerações finais}

Este trabalho tem como objetivo apresentar o retrato inicial de um jogo digital sobre o cálculo diferencial, um tema extremamente pertinente à inúmeras áreas do conhecimento, podendo até mesmo ser considerado básico para todos os cursos universitários relacionados às ciências exatas. Neste retrato, procuramos ilustrar os principais dilemas construtivos que nos levaram à cada uma das escolhas que viabilizaram o protótipo de "A Wild Function Appeared".

A importância desta abordagem se dá principalmente pela dificuldade em produzir jogos digitais que explorem esta temática, o que proporciona um baixo repertório para consulta sobre estes dilemas. Resultando para cada novo projeto, a repetição de erros que poderiam ser evitados se os registros de trabalhos correlatos também fossem consultados. Esperamos assim, contribuir para a fundamentação deste processo que mescla o game design ao desenvolvimento de recursos auxiliares à aprendizagem do cálculo diferencial.

Acrescentamos que a relação deste jogo digital com o pensamento computacional, que está intrinsecamente ligado à matemática como apresentado pela BNCC, se dá também pelos três exemplos apresentados no que diz respeito aos seus conceitos iniciais ("Handles in Scratch 2.0"; "Game-recover"; "ExQuest").

Como trabalhos futuros, esperamos realizar grupos de testes com o "A Wild Function Appeared", e também desenvolver seu aperfeiçoamento com recursos gráficos mais avançados, viabilizando assim o acréscimo de outros recursos e tornando-o visualmente mais atrativo. Visando também o aumento da sua semelhança com o contexto inicialmente proposto, tanto de divulgação científica da matemática, como sua direta relação ao jogo digital de gameboy, Pokémon versão red ou blue. Abaixo apresentamos um primeiro rascunho de como imaginamos este layout mais atrativo.

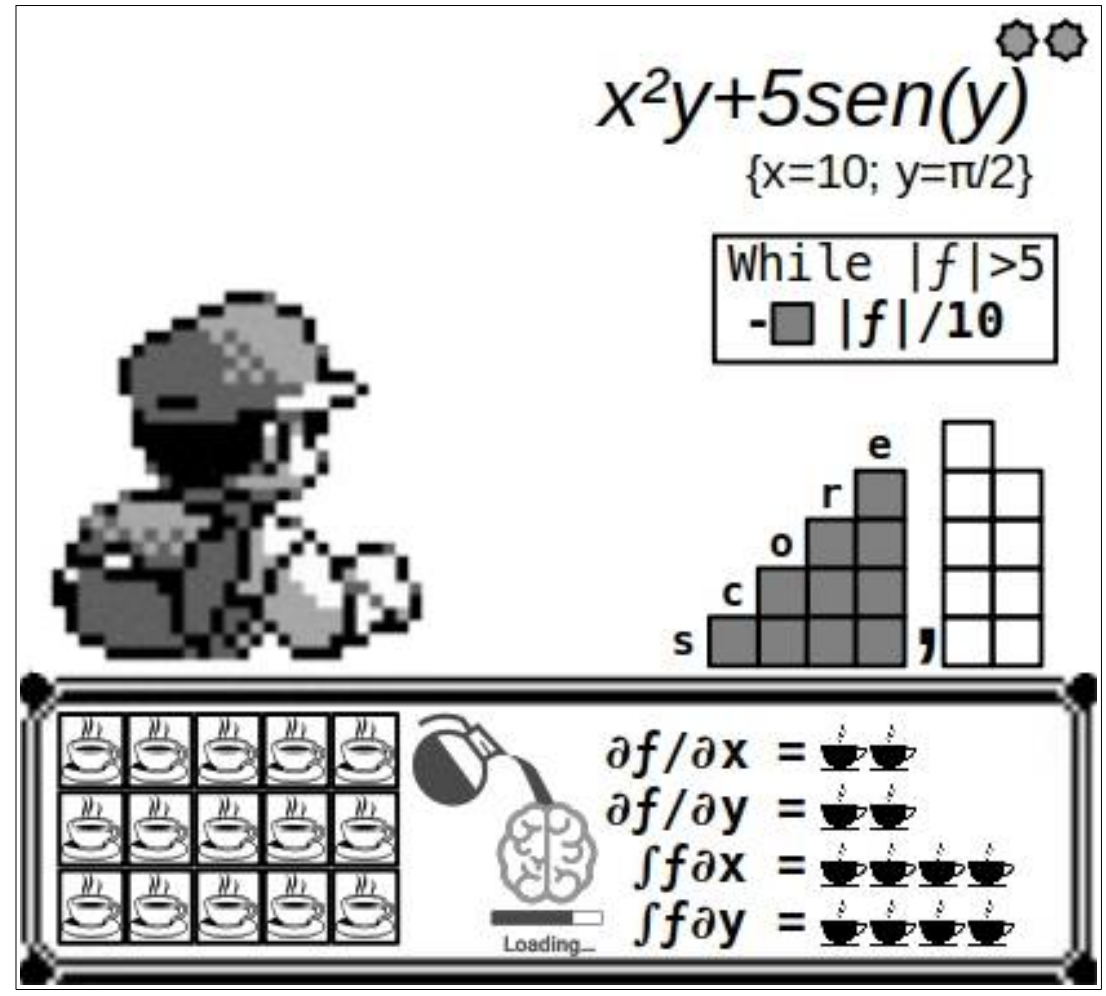

Figura 11 - Rascunho do layout idealizado para "A Wild Function Appeared” (fonte própria). 


\section{Referências}

BARR, V.; STEPHENSON, C. Bringing computational thinking to K-12: what is involved and what is the role of the computer science education community? ACM Inroads, v. 2, n. 1, p. 48-54, 2011.

CHANDLER, H. M. Manual de produção de jogos digitais. [S.1.]: Bookman, 2012.

COSTIKYAN, G. Uncertainty in games. Massachusetts: MIT Press, 2013.

GIL, A. C. Como elaborar projetos de pesquisa. 4. ed. São Paulo: Atlas, 2002.

KOJIMA, H.; TOGAMI, S. Guia mangá de cálculo: diferencial e integral. São Paulo: Novatec, 2010.

MOTTA, R. L.; TRIGUEIRO JUNIOR, J. Short game design document (SGDD): documento de game design aplicado a jogos de pequeno porte e advergames: um estudo de caso do advergame Rockergirl Bikeway. In: SIMPÓSIO BRASILEIRO DE JOGOS E ENTRETENIMENTO DIGITAL, 12., 2013, São Paulo. Proceedings [...] São Paulo: Universidade Presbiteriana Mackenzie, 2013. p. 115-121. Disponível em: sbgames.org/sbgames2013/proceedings/artedesign/15-dt-paper_SGDD.pdf. Acesso em: 25 ago. 2019.

OCHI, M.; ISHINO, T. Guia mangá: números complexos. São Paulo: Novatec Editora, 2010.

ROGERS, S. Level up: um guia para o design de grandes jogos. São Paulo: Blucher, 2012.

SILVA, M. H. P. D. ExQuest, um game sobre funções matemáticas em planilhas eletrônicas. In: ENCONTRO REGIONAL DE MATEMÁTICA APLICADA E COMPUTACIONAL, 6. 2019, Bauru. Caderno de trabalhos completos e resumos [...]. Bauru: Unesp, Faculdade de Ciências, 2019. p. 164-170. Disponível em: https://www.fc.unesp.br/\#!/departamentos/matematica/eventos2341/ermac-2019/caderno-de-trabalhos-e-resumos/. Acesso em: 30 out. 2019.

SILVA, M. H. P. D. A aprendizagem de métodos numéricos com o jogo digital Handles in Scratch 2.0. In: C.Q.D.-Revista Eletrônica Paulista de Matemática, Bauru, v. 10, p. 176193, dez. 2017. Edição Ermac.

SILVA, M. H. P. D. Game-Recover: um videojogo sobre consertar-se. In: SEMINÁRIO INTERNACIONAL COMUNIDADES DIGITAIS EM REDE, 1., 2018, Lisboa. Resumos Alargados [...]. Lisboa: UAb, 2018a, p. 31-32.

SILVA, M. H. P. D. Handles: a trajetória de desenvolvimento de um jogo digital para ensino de matemática. 2018. Dissertação (Mestrado em Educação para a Ciência) - Faculdade de Ciências, Universidade Estadual Paulista "Júlio de Mesquita Filho, Bauru, 2018b.

STEWART, J. Cálculo. 7. ed. São Paulo: Cengage Learning, 2013. v. 1.

WING, J. M. Computational thinking. Communications of the ACM, v. 49, n. 3, p. 33-35, 2006. 